\title{
Aportes para una planificación lingüística desde los pueblos indígenas en México
}

\author{
Jazmín Nallely Argüelles Santiago
}

Si consideramos que la planificación lingüística se refiere a las acciones concretas que se desarrollan en el contexto de realidades plurilingües o pluridialectales (Sichra, 2005), entonces podemos admitir que la planificación lingüística desde y para los países americanos debe ocuparse en poseer información lo suficientemente adecuada sobre el número de hablantes, su localización, la cultura de pertenencia, así como los espacios de utilización de todas las lenguas que en el interior de cada nación coexisten.

En el presente trabajo consideraré algunas controversias encontradas en la documentación proporcionada por el Instituto Nacional de Estadística, Geografía e Informática (INEGI), la Comisión para el desarrollo de los Pueblos Indígenas (CDI) y el Instituto Nacional de Lenguas Indígenas (INALI) respecto de los pueblos y lenguas indígenas en México. Asimismo, comenzaré a plantear determinadas acciones para la pervivencia de las lenguas minorizadas (status), producción de materiales (corpus) y ciertos indicadores para distinguir el uso y las estrategias de enseñanza en los espacios en donde las lenguas muestran su presencia (adquisición).

\section{¿Puede una clasificación de lenguas indígenas clasificar a los pueblos indígenas?}

En el caso de México los avances en materia de planificación lingüística están dados por la Ley General de Derechos Lingüísticos de los Pueblos Indígenas y la consecuente creación del Instituto Nacional de Lenguas indígenas, las modificaciones al Artículo 2 Constitucional, la reforma a la

O riginaria de Tepetzintla, Veracruz (México) e pertencente ao povo huasteco. Mestranda em Educación Intercultural Bilingüe pelo Programa de Formación en Educación Intercultural Bilingüe para los Países Andinos (PRO EIBAndes) e Universidad Mayor de San Simón (UMSS). jarguell@proeibandes.org 
fracción IV del Artículo 7 de la Ley General de Educación ${ }^{1}$, a la par de los trabajos que viene desarrollando la Comisión para el Desarrollo de los Pueblos Indígenas ${ }^{2}$ y el Instituto Nacional de Estadística, Geografía e Informática ${ }^{3}$.

Sin embargo, a pesar de los esfuerzos del gobierno mexicano en pro de sus lenguas nacionales y oficiales en los territorios donde se hablan, hoy en día aún no es posible identificar quiénes constituyen los pueblos indígenas, cuántos pueblos o culturas se asientan en el territorio de lo que ahora es México, cuántas lenguas son habladas y por quiénes. Esta tarea aún no ha termina de recabarse, la información disponible de modo digital por parte de instancias tales como el INALI, la CDI y el INEGI continúan con ciertas falencias en tanto no existe una determinada unificación de criterios para señalar cuántas lenguas y pueblos originarios existen en el país, peor aún la tendencia se dirige a asumir que el INALI es el único órgano oficial que estipula cuántas y cuáles lenguas indígenas se hablan en México.

Ciertamente, las agencias gubernamentales toman el papel protagónico en dichas delimitaciones y en escasa medida consideran el aporte de los usuarios. Si bien el Conteo de Población y Vivienda 2005 en relación con las personas que tenían 5 años o más preguntó acerca del nombre del estado y municipio en donde vivían en octubre del 2000 y si hablan alguna lengua indígena ${ }^{4}$, éste dejó de lado las situaciones de uso, las competencias lingüísticas, la información sobre L1 y L2 de cada hablante, así como el sentido de pertenencia a un pueblo o cultura.

Hasta ahora el INALI señala que existen 11 familias lingüísticas, 68 agrupaciones lingüísticas y 364 variantes dialectales ${ }^{5}$, sin embargo, en dichos datos no hay un intento por clasificar a los pueblos originarios. Inclusive, la conformación del Atlas de pueblos indígenas para América Latina y el Caribe tuvo que basarse en una clasificación de lenguas debido a que en nuestro país escasamente opera el binomio una lengua-una cultura. Las fichas, que debían llenarse para tal fin, tropezaban con la dificultad de clasificar diferentes familias lingüísticas-una cultura o un pueblo indígena-varias lenguas originarias. Fue necesario consultar las fuentes documentales proporcionadas por el INEGI, la CDI y el INALI respecto de las lenguas indígenas e indagar en monografías sobre las etnias que las ostentan para entender que los pueblos originarios en correspondencia con el uso de sus lenguas han enfrentado procesos históricos que los han ido moldeando hacia la conformación de una identidad cultural propia.

Dicha revisión dejó entrever principalmente tres situaciones. Primero, es posible advertir que diversos pueblos originarios hayan emi- 
grado y a su paso, se hayan fusionado con otros pueblos hasta adoptar la lengua del lugar de asentamiento o bien, mantener la suya y producir diferentes variedades dialectales.

Aún hoy existen denominaciones como "pimas del desierto" o "pimas altos" y "pimas de la sierra" o "pimas bajos". Los primeros han desaparecido prácticamente del territorio mexicano y los que habitaban en el noreste de Sonora terminaron por fusionarse con los pápagos, mientras que los pocos que quedan en Arizona habitan en la reservación india de Gila Bend. (Hope, 2006, p. 6)

De acuerdo con la autora, no hay más "pimas altos" en México, los únicos pimas localizados serían aquellos considerados como "pimas bajos". El INEGI encuentra a la lengua Pima dentro del grupo Pimano, perteneciente a la familia Yutoazteca (2006, p. 5) sin detenerse a considerar al pueblo indígena que la posee. El INALI tampoco enfatiza al pueblo originario, más bien distingue a la agrupación lingüística Pima de la familia Yuto-nahua con tres variantes, pima del norte (oob no' ok), pima del sur (oob no'ok) y pima del este (obnók) ${ }^{6}$. En todos los casos, si o' oba significa "la gente" y oob no' ok puede expresarse como "la gente que habla la lengua" (Hope, 2006), ¿por qué a pesar de estas inconsistencias continúa la clasificación "pima", siendo éste un término desde el castellano?, ¿es posible una clasificación que considere a los "oob no' ok" como un solo pueblo originario?

Segundo, existen indicios para señalar que algunos pueblos se mantuvieron como tales y permitieron el desarrollo de diferentes lenguas en su territorio. Veamos, los huastecos fueron un grupo maya que emigró hacia el noreste del Golfo de México y se extendió en los estados de Tamaulipas, Veracruz, San Luis Potosí e Hidalgo ${ }^{7}$. Sin embargo, por cuestiones de conquista, expansión del imperio Azteca y migraciones de otros pueblos, algunos huastecos fueron conquistados y adoptaron la lengua que aquellos últimos les heredaron. Ello, explica por qué en la Huasteca se habla el huasteco, otomí, tepehua y náhuatl. Elaborar una ficha exclusiva para el pueblo huasteco no sólo consideraría diferentes poblaciones en distintos estados de la República sino también diferentes familias lingüísticas, agrupaciones y variedades que, lejos de atomizar a los hablantes más bien constituyen rasgos que perfilan un mismo sentido de pertenencia, una identidad huasteca no basada en la lengua. Tal situación aún no cobra relevancia y sin duda merece atención.

En tercer lugar, ¿cómo avanzar hacia el reconocimiento de cuántos y cuáles pueblos coexisten en México si los nombres para denominarlos continúan dados por la supremacía de otros pueblos o culturas?, ¿es conveniente nombrar a los pueblos como se les ha conocido en el trans- 
curso de los años o es preferible priorizar la autodenominación que cada pueblo tiene y acepta? En el pasado, el poderío de los Aztecas determinó que quienes hablan "jnatrjo" o "jnatjio" - como aparece en el Catálogo 2007 - fueran conocidos como mazahuas, es decir, "hijos del venado" desde la lengua náhuatl. Hoy en día, el tema de las denominaciones por parte de las instituciones ha llegado al extremo de nombrar Oluteco al popoluca de Oluta y Texistepequeño al popoluca de Texistepec argumentando que "tanto oluteco como texistepequeño están en popoluca igual que otros pueblos que toman nombres de otra lengua, por ejemplo los mazahuas, matlazincas, otomíes..." (Fernando Nava, Director del INALI, comunicación personal), cuando ambos vocablos provienen del náhuatl y conforman un gentilicio desde el castellano. En virtud de tales situaciones, más que encontrar respuestas para una planificación lingüística regida por una clasificación de pueblos indígenas y sus respectivas lenguas originarias, es necesario aclarar:

- ¿cuáles son los marcadores de identidad cultural para los pueblos originarios?

- ¿cómo localizaríamos a los pueblos originarios, por el territorio de asentamiento o por la lengua de sus hablantes?

- ¿pueden las preguntas censales sobre lenguas vernáculas distinguir a quién es indígena de quien no lo es?

- ¿es posible una planificación lingüística basada únicamente en las lenguas originarias sin indagar sobre el pueblo indígena al que los pobladores adjudican su pertenencia?

\section{Somos huastecos, nuestra lengua es el náhuatl}

En el caso de los huastecos los marcadores de identidad cultural se fundamentan principalmente en el territorio, la lengua, el trabajo, la medicina tradicional, las festividades y las relaciones comerciales. La región conocida como Huasteca denota el sentido de pertenencia de los pobladores sin detenimiento en las divisiones convencionales que la sitúan en Tamaulipeca, Potosina, Hidalguense y Veracruzana. De manera lógica, los indígenas que habitan en esta región se consideran huastecos. Sin embargo, de acuerdo a los resultados que arrojan los censos una gran población huasteca no ha sido reconocida como tal. El conflicto radica en la lengua.

Como hemos visto, la pregunta del último Conteo en el 2005 solamente se refirió a la lengua que se habla no a la cultura de cada 
habitante. Si las respuestas eran náhuatl, otomí, tepehua o huasteco, únicamente estos últimos pasaban a conformar al pueblo originario huasteco mientras que el resto engrosaba la cantidad de hablantes de otras lenguas dejando entrever otros pueblos. Por otro lado, si el entrevistado radicado y nacido en la Huasteca respondía que no hablaba alguna lengua indígena, menos aún podía contabilizarse como parte del pueblo huasteco. Hasta ahora sólo se ha localizado a los pueblos por la lengua de sus hablantes no por el territorio en donde originalmente se han asentado. Si fuera posible un mapeo de pueblos indígenas basado en la cultura al que los pobladores adjudican su sentido de pertenencia, entonces el "pueblo nahua" comenzaría ha extinguirse. Al intentar localizarlo nos quedaría el reflejo de una nahuatización azteca ${ }^{8}$ en diferentes culturas. En este sentido, los huastecos de lengua náhuatl seríamos visibilizados como huastecos y no como nahuas de la Huasteca. A la fecha, los conteos y la CDI sólo han privilegiado a los huastecos hablantes de la lengua huasteca, cuya autodenominación es "tének" ${ }^{9}$. Sin embargo, los hablantes del náhuatl que han dejado atrás la lengua ancestral de este grupo cultural, aún mantienen una identidad huasteca. Cómo negarla si la denominación "huasteca" es un término que proviene originalmente del náhuatl: "koxtekatl" quiere decir "dueño del agua clara" ${ }^{10 "}$. No todos los huastecos somos "tének", también existimos los huastecos autodenominados "maseualmej" cuya lengua es el "naua tlajtoli".

\section{Para comenzar una planificación lingüística...}

Ciertamente una legislación y una documentación "oficial" en favor de los pueblos y lenguas indígenas no basta. Conviene analizar las potencialidades de una planificación lingüística que pueda ser considerada como un derecho indígena que fortalezca la identidad cultural. Si ello es posible y deseable por los actores inmediatos, habría que iniciar una planificación duradera, es decir, una planificación que considere el sentido de pertenencia a una cultura o pueblo originario de cada habitante y que comprometa a las agencias gubernamentales en la toma de responsabilidades para el desarrollo sostenible de todos los pueblos y todas las lenguas. De este modo, comenzarían experiencias locales con actores reales que paulatinamente llegasen a las instancias oficiales.

En este sentido, si el colectivo decide sobre tal o cuál lengua va a utilizar para la comunicación diaria, entonces la planeación del corpus consistiría en implementar acciones que coadyuven hacia la adquisición de las primeras y segundas lenguas reconocidas como locales $\mathrm{u}$ 
originarias. Desde mi punto de vista, es indispensable abrir espacios para que los expertos indígenas sean quienes otorguen el significado filosófico de las palabras y atiendan la ortografía de su lengua de modo que consigan cierta viabilidad práctica de la escritura cuestionando a los especialistas que frecuentemente articulan alfabetos fonológicos poco comprensibles para los usuarios. Así, los propietarios de las lenguas conseguirían oportunidades para expresar pensamientos, ideas y sentimientos desde sus propios marcos culturales de referencia basados en los principios comunitarios que permitan asegurar el acceso a la lengua no sólo a su documentación.

En cuanto a la adquisición, debemos partir aceptando que "lo fundamental de una lengua es que continúe siendo hablada (Meliá 2003, p. 22). Por ello, los miembros de cada familia y cada familia como esencia del pueblo originario pueden afianzar o revitalizar la lengua originaria de su contexto siempre y cuando la planificación de la adquisición sea accesible a sus formas de expresión.

Desde esta perspectiva, la construcción de una educación interculturalidad bilingüe compromete a todos. El uso de las lenguas indígenas tiene que ser asumido por el conjunto de las sociedades hegemónicas y pueblos originarios, de tal modo que permita incorporar la adquisición de una lengua indígena tanto en sectores discriminadores como discriminados, citadinos como rurales a fin de garantizar un Estado Mexicano pluricultural, plurilingüe y pluridialectal.

\section{Notas}

${ }^{1}$ En línea: http://www.inali.gob.mx/pdf/LGDLPI.pdf.

${ }^{2}$ En línea: http:/ / www.cdi.gob.mx.

${ }^{3}$ En línea: http://www.inegi.gob.mx.

${ }^{4}$ En línea: http://www.inegi.gob.mx/est/contenidos/espanol/proyectos/ conteos/conteo2005/difusion/Clase_Primaria.pdf.

${ }^{5}$ En línea http://www.inali.gob.mx/Catalogo2007.

${ }^{6}$ En línea: http://www.inali.gob.mx/Catálogo2007.

${ }^{7}$ En línea: http://www.conacyt.mx/Comunicaciones/Revista/193Articulo/ Huastecos/Huastecos02.htm.

${ }^{8}$ El Catálogo de Lenguas Indígenas considera que el náhuatl es una agrupación lingüística con treinta variedades, a las cuales otorga el grado de lenguas o idiomas.

${ }^{9}$ En línea: http://www.cdi.gob.mx/index.php?id_seccion=660.

${ }^{10}$ El significado fue analizado según dos expertos indígenas del municipio de Tepetzintla, Veracruz. Don Evaristo vive en la comunidad de Tecomate y Doña Julia en la cabecera municipal. 


\section{Referencias}

MELIÀ, Bartomeu. El silencio de las lenguas y la palabra recuperada. In: SOLÍS, Gustavo (ed.) Cuestiones de Lingüística Amerindia. In: TERCER CONGRESO NACIONAL DE INVESTIGACIONES LINGÜÍSTICO-FILOLÓGICAS. Lima: La Molina/ PROEIB Andes/GTZ/ UNMSM, 2003. p. 21-36.

SICHRA, Inge. ¿Qué hacemos para las lenguas indígenas? ¿Qué podemos hacer? ¿Qué debemos hacer? Reflexiones sobre la práctica y teoría de planificación lingüística. El hablante tiene la última palabra. Revista de Educación Intercultural Bilingüe Quinasay. La Paz, v. 3, p.161-81, 2005.

MÉXICO. Comisión Nacional para el Desarrollo de los Pueblos Indígenas. Lenguas Indígenas de México, 2005. Disponible en: <http://www.cdi.gob.mx/index.php? id_seccion $=660>$.

HOPE, Margarita. Pimas. México, DF: CDI-PNUD, 2006.

MÉXICO. Instituto Nacional de Lenguas Indígenas. Ley General de Derechos Lingüísticos de los Pueblos Indígenas. 2003. Disponible en: <http:/ / www.inali.gob.mx /pdf/LGDLPI.pdf>.

MÉXICO. Catálogo de lenguas indígenas nacionales: Variantes lingüísticas de México con sus autodenominaciones y referencias geoestadísticas, 2007. Disponible en: <http://www.inali.gob.mx/Catalogo2007>.

MÉXICO. Instituto Nacional de Estadística, Geografía e Informática. Clasificación de lenguas indígenas. In: II CONTEO DE POBLACIÓN Y VIVIENDA, 2005. Clase alusiva al Conteo para Primaria. 2006, México, DF: DGE-INEGI. Disponible en: <http://www.inegi.gob.mx/est/contenidos/espanol/proyectos/conteos/ conteo2005/difusion/Clase_Primaria.pdf>.

RAMÍREZ CASTILLO, Gustavo A. Huastecos, entre el mito y la historia, 2000. Disponible en: <http://www.conacyt/comunicaciones/revista/193Articulo/Huastecos/ Huastecos02.htm>.

Recebido em 27 de fevereiro de 2008.

Aprovado para publicação em 07 de março de 2008. 
